\title{
Bir Tekstil Fabrikasının Çalışanlarında Sağlık Okuryazarlığı Düzeyi ve ilişkili Etmenler
}

\author{
Health Literacy Level and Related Factors Among Employees of a Textile Factory
}

\author{
Güliz AYDEMIR ACAR (D) , Kerim BALTACI iD , Nurhan MEYDAN ACIMIŞ (i) , Onur ORHAN
}

\begin{abstract}
ÖZET
Tanımlayıcı-kesitsel tipteki epidemiyolojik araştırmanın amacı tekstil fabrikası çalışanlarının sağlı okuryazarlığı düzeyini tespit etmek ve ilişkili etmenleri belirlemektir. Örnek büyüklüğü ortalama 29 , standart sapma 3 , tip 1 hata düzeyi $\% 5$ kabul edilerek \%95 güven aralığında 360 kişi hesaplanmıștır. Çalıșmayı kabul edenlerin hepsi araștırmaya dahil edilmiștir. Araştırmanın veri toplama aracı 70 sorudan oluşan anket formudur. Katılımcıların sağlık okuryazarlığı düzeyi, Türkiye Sağlık Okuryazarlı̆ı Ölçeği (TSOY-32) ile değerlendirilmiștir. Verilerin istatistiksel analizinde Statistical Package for the Social Sciences (SPSS) versiyon 18.0 kullanılmıştır. p<0,05 anlamlı kabul edilmiştir. Araştırmaya 260 kişi katıldı. Katılımcıların \% 21,2 'si yetersiz, \%35,2'si sorunlu-sınırl, \%28,8'i yeterli, \%14,8'i mükemmel sağllk okuryazarlığı düzeyine sahipti. Yeterlimükemmel sağlı okuryazarlığı düzeyini, lise ve üzeri eğitime sahip olmak 1,96 kat (GA=1,05-3,63, p=0,033), iş ile ilgili sağlık ve güvenlik talimatlarını anlamada zorluk yaşamamak 3,10 kat (GA=1,35-7,07, $\mathrm{p}=0,007)$ arttırmaktaydı. Çalışanların yarıya yakınında sağlı okuryazarlığı düzeyi yetersiz veya sorunlu-sınırlıdır. Eğitim düzeyi sağlık okuryazarlığı düzeyi için önemli bir belirleyicidir. İş sağlğ̆ı ve güvenliği talimatlarını anlamada zorluk yaşayanların sağlık okuryazarlığı düzeyi düşüktür.

Anahtar Kelimeler: Dokuma sanayi, İş sağlığı, Sağlık eğitimi, Sağlık okuryazarlığı
\end{abstract}

\section{ABSTRACT}

Purpose of the descriptive-cross sectional epidemiological research is to determine the health literacy level of textile factory employees and to determine the related factors. The sample size was calculated as 360 people, with a mean of 29 , a standard deviation of 3, and a type 1 error level of $5 \%$, with a $95 \%$ confidence interval. All those who accepted the research were included in the research. The data collection tool of the research was a questionnaire consisting of 70 questions. The health literacy level of the participants was evaluated with the Turkish Health Literacy Scale (TSOY-32). Statistical Package for the Social Sciences (SPSS) version 18.0 was used for statistical analysis of the data. $p<0.05$ was considered significant. 260 people participated in the research. $21.2 \%$ of the participants had inadequate, $35.2 \%$ problematic-limited, $28.8 \%$ adequate and $14.8 \%$ excellent health literacy levels. Having a high school or higher education 1.96 times (CI=1.05-3.63, $\mathrm{p}=0.033$ ), not having difficulty understanding occupational health and safety instructions 3.10 times (CI=1.35-7.07) , $\mathrm{p}=0.007$ ) increased the level of adequate-perfect health literacy. Almost half of the employees have insufficient or problematic-limited level of health literacy. Education level is an important determinant of health literacy level. The health literacy level of those who have difficulty in understanding the occupational health and safety instructions is also low.

Keywords: Health education, Health literacy, Occupational health, Textile industry

Güliz AYDEMIR ACAR | glz.1986@outlook.com

Niğde III Sağlık Müdürlüğü, Niğde, Türkiye

Nigde Provincial Health Directorate, Nigde, Turkey

Nurhan MEYDAN ACIMIŞ | nurhan88@hotmail.com

Pamukkale Üniv., Tıp Fakültesi Halk Sağlığı Anabilim Dalı, Denizli, Türkiye Pamukkale Univ., Faculty of Medicine, Dept. of Public Health, Denizli, Turkey

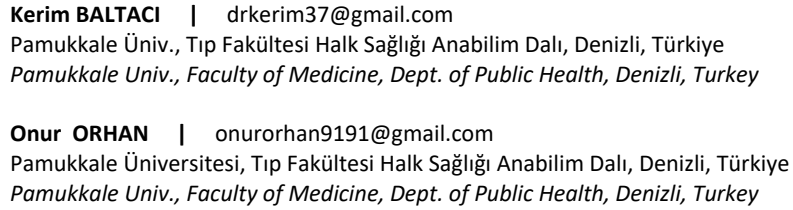




\section{GİRİŞ}

Sağlık okuryazarlı̆̆ı̆ (SOY), Dünya Sağlık Örgütü’ne (DSÖ) göre, sağlıkta iyilik halini korumak ve geliştirmek amacıyla bireylerin sağlık bilgisine erişim, bilgiyi anlama ve kullanma kabiliyetleri ile istekleri konusundaki bilişsel ve sosyal becerileridir [1]. Düşük sağlık okuryazarlığı istenmeyen sağlık sonuçlarına, daha fazla hastane yatışlarına ve koruyucu sağlık hizmetlerinin daha az kullanılmasına neden olabilmektedir. Araştırmalar sağlık okuryazarlığının düşük olduğu toplumlarda sağlık bakım maliyetlerinin yüksek olduğunu göstermektedir [1,2].

Sağlık okuryazarllğ̆ı toplumun tüm kesimini yakından ilgilendiren önemli bir konudur ve işyerleri için de gerekli bir unsurdur. Sağlık okuryazarlığından yola çıkılarak geliştirilen iş sağlığı okuryazarlığı kavramı, iş sağlığı ve güvenliği bilgilerini ve hizmetlerini elde etme, iletme, işleme ve anlama kapasitesine sahip olma derecesini ifade etmektedir [3]. İşyeri kaza ve yaralanmalarının azaltılmasında, iş ile ilgili tehlike ve risklerin kontrolünde alınan mühendislik önlemleri etkin olsa da, sağlık okuryazarllğının geliştirilmesi de önemli bir role sahiptir. Düşük sağlık okuryazarlığına sahip çalışanlar işle ilgili yaralanmalar ve kazalar bakımından savunmasız ve riskli gruplar olarak kabul edilmektedir $[4,5]$. İşe bağlı fiziksel, kimyasal, biyolojik, psikososyal tehlikelere maruziyet, düşük SOY ile birleştiğinde kaza, yaralanma ve meslek hastalığı olasılığının azaltılmasında kaçınılmaz bir rol almaktadır [6]. Araştırmalar işyerinde sağlık okuryazarlığının geliştirilmesi ile daha iyi sağlık çıktılarının elde edilebileceğini göstermektedir [1]. Çalışan nüfusun zamanının büyük bir çoğunluğunu işyerinde geçirmesi, bireylerin toplu halde bulunması nedeniyle işyerleri sağlığın korunması ve geliştirilmesi açısından uygun ortamlardır. Gerek sağlıklı davranış biçimlerinin kazandırılabilmesi gerekse iş sağlığı ve güvenliği eğitimlerinin amacına ulaşabilmesi için çalışanların SOY düzeyinin arttırılması gerekmektedir.

Geleneksel iş sağlığı ve güvenliği çoğunlukla işyeri risk analizine, teknik önlemlere ve iş sağlı̆̆ı ve güvenliği ile ilgili eğitimlere odaklanmaktadır [7]. İşyerinde sağlık okuryazarlığını düzeyini iyileştirmek için gerekli müdahalelerin belirlenmesinde çalışanların sağlık okuryazarlığı düzeyinin ve ilişkili olduğu faktörlerin belirlenmesi gerekmektedir. Çalışan nüfusta sağılı okuryazarlığının araştırıldığı çalışma sayısı çok azdır. Nispeten eğitim düzeyi diğer sektörlere göre daha düşük olan çalş̧anların sağlık okuryazarlı̆̆ı düzeyinin belirlenmesine ihtiyaç vardır.

$\mathrm{Bu}$ araştırmanın amacı az tehlikeli sınıfta yer alan bir tekstil fabrikasında çalışanların SOY düzeyini tespit etmek ve SOY ile ilişkili bazı etmenleri belirlemektir.

\section{YÖNTEM}

\section{A. Araştırma Tipi}

Araştırma tanımlayıcı-kesitsel tipte bir epidemiyolojik araştırmadır.

\section{B. Evren ve Örneklem}

Araştırmanın evrenini Denizli ilindeki bir tekstil fabrikasında çalışanlar oluşturmuştur. Evreni bilinmeyen örneklem büyüklüğü hesaplama formülüne göre ortalama 29 , standart sapma 3, tip 1 hata düzeyi \%5 kabul edilerek \%95 güven aralığında evreni temsil edecek örnek büyüklüğü 360 kişi olarak hesaplanmıştır. Örneklem seçimine gidilmemiş olup çalı̧̧mayı kabul edenlerin hepsi araştırmaya dahil edilmiştir.

\section{Araştırma İzinleri}

Pamukkale Üniversitesi Tip Fakültesi Girişimsel Olmayan Klinik Araştırmalar Etik Kurulu’ndan etik kurul izinleri ve kurumsal izinler alınmıştır. Katılımcılardan sözlü izin 
alınmıştır.

\section{Veri Toplama Yöntemi}

Araştırmanın verileri 22 Temmuz-9 Ağustos 2019 tarihleri arasında toplanmıştır. Araştırmanın verileri çalışanların sağlık okuryazarları düzeyini ve etkileyen faktörleri sorgulayan anket formunun çalışmaya katılmaya gönüllü katılımcılar tarafından doldurulması yoluyla toplanmıştır. Veri toplama aracı TSOY-32 ölçeği ile katılımcıların bazı özelliklerini sorgulayan anket formundan oluşmaktadır.

Katılımcıların sağlık okuryazarlık düzeyi, Okyay ve ark. tarafından geliştirilmiş olan Türkiye Sağlık Okuryazarlığı Ölçeği (TSOY-32) ile değerlendirilmiştir. Ölçek, tedavi ve hizmet alt boyutu ile hastalıklardan korunma ve sağlığın geliştirilmesi alt boyutlarından oluşmaktadır. Cronbach alfa katsayısı değerleri sırasıyla 0,880 ve 0,863 'tür. Ölçeğin tümü için bu değer 0,927'dir. TSOY ölçeği 32 sorudan oluşan, beşli likert tipindedir. Her madde; çok kolay (4), kolay (3), zor (2), çok zor (1) ve fikrim yok (0) şeklinde likert tipindedir. Ölçekten alınabilecek toplam puan hesaplama kolaylığı açısından 0-50 arası değer alacak şekilde formalize [indeks $=($ ortalama-1) $\mathrm{x}(50 / 3)]$ edilmiştir. Ölçekten alınabilecek puanlar 0-50 aralığında dağılım göstermektedir ve 0 (sıfır) puan yetersiz sağlık okuryazarlığı düzeyini gösterirken, 50 puan mükemmel sağlık okuryazarlığı düzeyini göstermektedir.

Soru formunda; 10 soru katılımciların sosyodemografik özelliklerini, 9 soru genel sağlık özelliklerini, 10 soru mesleki özelliklerini, 9 soru işyeri tehlike ve güvenlik işaretleri hakkında bilgi düzeyini sorgulamaktadır. Tehlike ve güvenlik işaretlerinin her birinin anlamını doğru bilenler "1" puan, yanlış bilenler “0” puan almıştır. Tehlike ve güvenlik işareti bilgi puanı 0-9 aralığında dağılım göstermektedir.

\section{E. Bağımlı ve Bağımsız Değişkenler}

Araştırmanın bağımlı değişkeni TSOY-32 ölçeğinden alınan puandır. Bağımsız değişkenler katılımcıların bazı sosyo-demografik özellikleri, genel sağlık özellikleri, mesleki özellikleri ile işyeri tehlike ve güvenlik işaretlerine yönelik elde edilen bilgi puanıdır.

\section{F. Veri Analizi}

Verilerin istatistiksel analizinde Statistical Package for the Social Sciences (SPSS, 18.0, Chicago) kullanılmıştır. Değişkenlere ilişkin tanımlayıcı istatistikler sayı, yüzde, ortalama ve standart sapma hesaplanarak verilmiştir. Verilerin normal dağılıma uygunluğu Kolmogrov-Smirnov ve Shapiro-Wilk testleri ile değerlendirilmiştir. Gruplar arasında SOY düzeyi bakımından fark bulunup bulunmadığ Pearson Ki-kare testi ile karşılaştırılmıştır. Dört gözlü tablolarda beklenen değerler çapraz tablonun gözlerinin \% 20'sinden çoğunda 5'ten küçükse Fisher testi ile söz konusu karşılaştırmalar yapılmıştır. SOY düzeyi ile ilişkili bağımsız risk faktörleri çok değişkenli lojistik regresyon analizi (backward wald) ile incelenmiştir. İkili analizlerde istatistiksel olarak anlamlı bulunan değişkenler (Algılanan gelir, sağlık algısı, aile tipi, eğitim durumu, işi tehlikeli olarak algılama, işle ilgili sağlık ve güvenlik talimatlarını anlamada zorluk) lojistik regresyon modeline dahil edilmiştir. $\mathrm{p}<0,05$ ise anlamlı kabul edildi.

\section{BULGULAR}

Araştırmada 260 kişiye ulaşılmıştır. 24 anket formu, ölçek sorularının \%50'sinden fazlasının eksik cevaplanmasından dolayı analize dahil edilmemiştir. Araştırmaya katı-

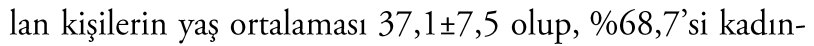
dır. Katılımcıların \%69,4’ü ortaokul ve üstü eğitim düzeyine sahiptir. \%43,6'sı sağlığını “iyi-fena değil” olarak değerlendirmiştir. Katılımcıların \%75,7’si sağlık ile ilgili bilgileri 
sağlık personelinden aldığını belirtmiştir (Tablo 1).

Tablo 1: Katılımcıların bazı sosyodemografik ve genel sağlık özelliklerinin dağılımı

\begin{tabular}{|c|c|c|c|}
\hline & & $\begin{array}{l}\text { Sayı } \\
\text { (n) }\end{array}$ & $\begin{array}{c}\text { Yüzde } \\
(\%)\end{array}$ \\
\hline \multirow{2}{*}{ Yaş } & 20-39 yaş & 139 & 62,3 \\
\hline & 40 yaş ve üstü & 84 & 37,7 \\
\hline \multirow{2}{*}{ Cinsiyet } & Kadın & 158 & 68,7 \\
\hline & Erkek & 72 & 31,3 \\
\hline \multirow{3}{*}{ Medeni durum } & Evli & 176 & 77,2 \\
\hline & Bekar & 27 & 11,8 \\
\hline & $\begin{array}{l}\text { yor } \\
\text { yor }\end{array}$ & 25 & 11,0 \\
\hline \multirow{2}{*}{ Çocuk varlığı } & Var & 191 & 82,0 \\
\hline & Yok & 42 & 18,0 \\
\hline \multirow{3}{*}{ Aile tipi } & Çekirdek aile & 174 & 76,0 \\
\hline & Geniş aile & 32 & 14,0 \\
\hline & Parçalanmış aile & 23 & 10,0 \\
\hline \multirow{2}{*}{ Eğitim durumu } & Ortaokul ve alt & 161 & 69,4 \\
\hline & Lise ve üzeri & 71 & 30,6 \\
\hline \multirow{3}{*}{ Gelir durumu } & Gelir giderden az & 114 & 49,8 \\
\hline & Gelir gidere eşit & 85 & 37,1 \\
\hline & Gelir giderden fazla & 30 & 13,1 \\
\hline \multirow{2}{*}{ Sosyal güvence } & Var & 230 & 99,1 \\
\hline & Yok & 2 & 0,9 \\
\hline \multirow{2}{*}{$\begin{array}{l}\text { En uzun süre } \\
\text { yaşanılan yer }\end{array}$} & Kırsal & 58 & 24,6 \\
\hline & Kentsel & 178 & 75,4 \\
\hline \multirow{3}{*}{ Sağlık algısı } & Mükemmel/Oldukça iyi & 41 & 17,5 \\
\hline & İyi & 102 & 43,6 \\
\hline & Fena değil-kötü & 91 & 38,9 \\
\hline \multirow{4}{*}{$\begin{array}{l}\text { Beden kitle } \\
\text { indeksi }\end{array}$} & Zayıf & 3 & 1,4 \\
\hline & Normal & 104 & 47,5 \\
\hline & Fazla kilolu & 77 & 35,1 \\
\hline & Obez & 35 & 16,0 \\
\hline \multirow{2}{*}{ Diyet } & Yapan & 157 & 66,8 \\
\hline & Yapmayan & 78 & 33,2 \\
\hline \multirow{2}{*}{ Sigara } & İçiyor & 61 & 25,8 \\
\hline & İçmiyor & 175 & 74,2 \\
\hline \multirow{2}{*}{ Alkol } & Kullanıyor & 48 & 20,6 \\
\hline & Kullanmıyor & 185 & 79,4 \\
\hline \multirow{3}{*}{$\begin{array}{l}\text { Sağlık bilgisine } \\
\text { erişim }\end{array}$} & Medya & 47 & 20,4 \\
\hline & Yakın çevre & 9 & 3,9 \\
\hline & Sağlık personeli & 174 & 75,7 \\
\hline \multirow{2}{*}{ Kronik hastalık } & Var & 53 & 22,7 \\
\hline & Yok & 180 & 77,3 \\
\hline
\end{tabular}

Katılımciların \%12,0'1 $(\mathrm{n}=28)$ idari personel, \%88,0'1 (n=206) tekstil bölümü çalışanıdır. \%75,0’’nın (n=174) 110 yıl ve \%25'inin ( $\mathrm{n}=58) 10$ yılın üstünde mesleki deneyimi bulunmaktadır. Çalışmaya katılanların \%19,7’si işini tehlikeli olarak algıladığını, \%8,1'i iş ile ilgili bir kaza geçir- diğini ve \%21,0’ı işle ilgili talimatları anlamada zorluk yaşadığını ifade etmiştir (Tablo 2).

Tablo 2: Katılımcıların iş ile ilgili bazı özelliklerinin dağılımı

\begin{tabular}{|c|c|c|c|}
\hline & & Sayı (n) & Yüzde (\%) \\
\hline \multirow{2}{*}{ İşini tehlikeli algılama } & Tehlikeli & 43 & 19,7 \\
\hline & Tehlikesiz & 175 & 80,3 \\
\hline \multirow{2}{*}{$\begin{array}{l}\text { İşinin tehlike sınıfinı } \\
\text { bilme }\end{array}$} & Bilen & 199 & 87,3 \\
\hline & Bilmeyen & 29 & 12,7 \\
\hline \multirow{2}{*}{ İş kazası geçirme } & Evet & 19 & 8,1 \\
\hline & Hayır & 216 & 91,9 \\
\hline \multirow{3}{*}{$\begin{array}{l}\text { İşyeri sağlık ve güvenlik } \\
\text { talimatlarını anlamada } \\
\text { zorluk }\end{array}$} & Evet/Kısmen & & \\
\hline & Hayır & 49 & 21,0 \\
\hline & & 184 & 79,0 \\
\hline \multirow{2}{*}{$\begin{array}{l}\text { Kişisel koruyucu dona- } \\
\text { nım }\end{array}$} & Kullanan & 145 & 65,9 \\
\hline & Kullanmayan & 75 & 34,1 \\
\hline \multirow{2}{*}{ İlk yardım eğitimi } & Alan & 125 & 53,9 \\
\hline & Almayan & 107 & 46,1 \\
\hline \multirow{2}{*}{ iSG* eğitimi } & Alan & 213 & 91,0 \\
\hline & Almayan & 21 & 9,0 \\
\hline \multirow{2}{*}{$\begin{array}{l}\text { İşyeri tehlike ve güvenlik } \\
\text { işareti bilgi puanı }\end{array}$} & 8 puan ve alt & 120 & 56,9 \\
\hline & 9 puanın üstü & 91 & 43,1 \\
\hline
\end{tabular}

Katılımcıların SOY düzeyi değerlendirildiğinde \% 21,2'sinin yetersiz, \%35,2'sinin sorunlu-sınırlı, \%28,8'inin yeterli, \%14,8'inin mükemmel olduğu bulunmuştur (Tablo 3).

Tablo 3: Katılımcıların sağlık okuryazarlığı düzeylerinin dağılımı

\begin{tabular}{lcc}
\hline Sağlık okuryazarlığı düzeyi & Sayı (n) & Yüzde (\%) \\
\hline Yetersiz & 50 & 21,2 \\
Sorunlu-sınırlı & 83 & 35,2 \\
Yeterli & 68 & 28,8 \\
Mükemmel & 35 & 14,8 \\
\hline
\end{tabular}

Eğitim düzeyi ortaokul ve altı olanların \%62,7'sinin $(\mathrm{n}=101)$, lise ve üzeri olanların $\% 45,1^{\prime}$ inin $(\mathrm{n}=32)$ SOY düzeyi yetersiz-sorunlu/sınırlı olup, ortaokul ve altı olanların SOY düzeyi lise ve üzeri olanlara kıyasla daha düşük bulunmuştur ( $\mathrm{p}=0,014)$. Çekirdek aileye sahip olanların \% 51,7’sinin $(n=90)$, geniş ailede yaşayanların \%65,6'sının ( $n=21)$, aile bütünlüğü bozulmuş bireylerin \%78,3'ünün (n=18) SOY düzeyi yetersiz-sorunlu/sınırlı olup, aile bütünlüğü bozulmuş kişilerin SOY düzeyi diğer aile tiplerine 
Tablo 4. Katılımcıların bazı özelliklerine göre sağlık okuryazarlığı düzeylerinin dağılımı

\begin{tabular}{|c|c|c|c|c|}
\hline & & Yetersiz/Sorunlu-Sınırlı & Yeterli/Mükemmel & p* \\
\hline & & Sayı (n) Yüzde (\%) & Sayı (n) Yüzde (\%) & \\
\hline \multirow{2}{*}{ Yaş } & $20-39$ yaş & $73(52,5)$ & $66(47,5)$ & \multirow{2}{*}{0,085} \\
\hline & 40 yaş ve üstü & $54(64,3)$ & $30(35,7)$ & \\
\hline \multirow{2}{*}{ Cinsiyet } & Kadın & $88(55,7)$ & $70(44,3)$ & \multirow{2}{*}{0,567} \\
\hline & Erkek & $43(59,7)$ & $29(40,3)$ & \\
\hline \multirow{3}{*}{ Medeni durum } & \multirow{3}{*}{$\begin{array}{l}\text { Evli } \\
\text { Bekar } \\
\text { Dul/Boşanmış/Ayrı yaşı- } \\
\text { yor }\end{array}$} & $96(54,5)$ & $80(45,5)$ & \multirow{3}{*}{0,230} \\
\hline & & $14(51,9)$ & $13(48,1)$ & \\
\hline & & $18(72,0)$ & $7(28,0)$ & \\
\hline \multirow{2}{*}{ Çocuk varlığı } & Var & $107(56,0)$ & $84(44,0)$ & \multirow{2}{*}{0,894} \\
\hline & Yok & $24(57,1)$ & $18(42,9)$ & \\
\hline \multirow{3}{*}{ Aile tipi } & Çekirdek aile & $90(51,7)$ & $84(48,3)$ & \multirow{3}{*}{0,028} \\
\hline & Geniş aile & $21(65,6)$ & $11(34,4)$ & \\
\hline & Parçalanmış aile & $18(78,3)$ & $5(21,7)$ & \\
\hline \multirow{2}{*}{ Eğitim durumu } & Ortaokul ve alt & $101(62,7)$ & $60(37,3)$ & \multirow{2}{*}{0,012} \\
\hline & Lise ve üzeri & $32(45,1)$ & $39(54,9)$ & \\
\hline \multirow{3}{*}{ Gelir durumu } & Gelir giderden az & $74(64,9)$ & $40(35,1)$ & \multirow{3}{*}{0,012} \\
\hline & Gelir gidere eşit & $44(51,8)$ & $41(48,2)$ & \\
\hline & Gelir giderden fazla & $11(36,7)$ & $19(63,3)$ & \\
\hline \multirow{2}{*}{ Sosyal güvence } & Var & $129(56,1)$ & $101(43,9)$ & \multirow{2}{*}{$1,000 * *$} \\
\hline & Yok & $1(50,0)$ & $1(50,0)$ & \\
\hline En uzun süre yaşanılan & Kırsal & $37(63,8)$ & $21(36,2)$ & 0189 \\
\hline & Kentsel & $96(53,9)$ & $82(46,1)$ & 0,189 \\
\hline & Mükemmel/Oldukça iyi & $17(41,5)$ & $24(58,5)$ & \\
\hline Sağlık algısı & İyi & $51(50,0)$ & $51(50,0)$ & 0,002 \\
\hline & Fena değil-kötü & $64(70,3)$ & $27(29,7)$ & \\
\hline & Zayıf/Normal & $55(51,4)$ & $52(48,6)$ & \\
\hline Beden kitle indeksi & Fazla kilolu/Obez & $67(59,8)$ & $45(40,2)$ & 0,210 \\
\hline & Yapan & $86(54,8)$ & $71(45,2)$ & \\
\hline Diyet & Yapmayan & $46(59,0)$ & $32(41,0)$ & 0,541 \\
\hline & İçiyor & $36(59,0)$ & $25(41,0)$ & \\
\hline Sigara & İçmiyor & $97(55,4)$ & $78(44,6)$ & 0,627 \\
\hline Alkol & Kullanıyor & $30(62,5)$ & $18(37,5)$ & 0294 \\
\hline Alkol & Kullanmıyor & $100(54,1)$ & $85(45,9)$ & 0,294 \\
\hline & Medya & $24(51,1)$ & $23(48,9)$ & \\
\hline Sağlık bilgisine erişim & Yakın çevre & $8(88,9)$ & $1(11,1)$ & 0,110 \\
\hline & Sağlık personeli & $97(55,4)$ & $77(44,3)$ & \\
\hline & Var & $34(64,2)$ & $19(35,8)$ & \\
\hline Kronik hastalık & Yok & $98(54,4)$ & $82(45,6)$ & 0,210 \\
\hline & İdari personel & $16(57,1)$ & $12(42,9)$ & \\
\hline Işteki pozisyonu & Çalışan & $115(55,8)$ & $91(44,2)$ & 0,895 \\
\hline & $1-10 \mathrm{yll}$ & $99(56,9)$ & $75(43,1)$ & \\
\hline Çalışma yılı & 10 yılın üstünde & $32(55,2)$ & $26(44,8)$ & 0,819 \\
\hline & Tehlikeli & $30(69,8)$ & $13(30,2)$ & \\
\hline Işini tehlikeli algılama & Tehlikesiz & $91(52,0)$ & $84(48,0)$ & 0,036 \\
\hline & Bilen & $107(53,8)$ & $92(46,2)$ & \\
\hline Işinin tehlike sınıfinı bilme & Bilmeyen & $21(72,4)$ & $8(27,6)$ & 0,059 \\
\hline j̇s kazası gecirme & Evet & $11(57,9)$ & $8(42,1)$ & \\
\hline Iş kazası geçirme & Hayır & $121(56,0)$ & $95(44,0)$ & 0,874 \\
\hline İşyeri sağlık ve güvenlik & Evet/Kısmen & $38(77,6)$ & $11(22,4)$ & \\
\hline $\begin{array}{l}\text { talimatlarını anlamada } \\
\text { zorluk }\end{array}$ & Hayır & $93(50,5)$ & $91(49,5)$ & 0,001 \\
\hline & Kullanan & $84(57,9)$ & $61(42,1)$ & \\
\hline Kişisel koruyucu donanım & Kullanmayan & $40(53,3)$ & $35(46,7)$ & 0,515 \\
\hline & Alan & $68(54,4)$ & $57(45,6)$ & \\
\hline Ilk yardım egitimi & Almayan & $62(57,9)$ & $45(42,1)$ & 0,588 \\
\hline iSG eğitimi & Alan & $119(55,9)$ & $94(44,1)$ & 0.911 \\
\hline ISG eğitimi & Almayan & $12(57,1)$ & $9(42,9)$ & 0,911 \\
\hline İşyeri tehlike ve güvenlik & 8 puan ve alt & $72(60,0)$ & $48(40,0)$ & \\
\hline işareti bilgi puanı & 9 puanın üstü & $47(51,6)$ & $44(48,4)$ & 0,226 \\
\hline
\end{tabular}


göre daha düşüktür $(\mathrm{p}=0,028)$. Geliri giderinden fazla olanların \%36,7'sinin ( $\mathrm{n}=11)$, geliri giderine eşit olanların $\% 51,8^{\prime}$ inin ( $\left.\mathrm{n}=44\right)$, geliri giderinden az olanların \% 64,9'unun (n=74) SOY düzeyi yetersiz-sorunlu/sınırlı olup, gelir durumu iyi bireylere göre geliri düşük bireylerde SOY düzeyi düşük bulunmuştur ( $\mathrm{p}=0,012)$. Sağlığını mükemmel-oldukça iyi olarak değerlendirenlerin \%41,5'inin $(\mathrm{n}=17)$, iyi olarak değerlendirenlerin $\% 50,0^{\prime} \mathrm{n} n \mathrm{n}(\mathrm{n}=51)$, fena değil-kötü olarak değerlendirenlerin \%70,3’ünün ( $\mathrm{n}=64)$ SOY düzeyi yetersiz-sorunlu/sınırlı olup, sağlığını kötü olarak değerlendirenlerde SOY düzeyi düşük bulunmuştur ( $\mathrm{p}=0,002)$. İşini tehlikeli algılayanların \%69,8'inin $(\mathrm{n}=30)$, algılamayanların \%52,0'ının ( $\mathrm{n}=91)$ SOY düzeyi yetersiz-sorunlu/sınırlıdır ( $\mathrm{p}=0,036)$. Talimatları algılamada zorluk yaşayanların $\% 77,6$ 'sının $(\mathrm{n}=38)$, zorluk yaşamayanların \%50,5’inin ( $\mathrm{n}=93$ ) SOY düzeyi yetersiz-sorunlu/ sınırlı olup, işyeri sağlık ve güvenlik talimatlarını anlamada zorluk yaşayanlarda zorluk yaşamayanlara kıyasla SOY düzeyi düşük bulunmuştur ( $\mathrm{p}=0,001)$. Katılımcıların diğer sosyodemografik, genel sağlık ve mesleki özellikleri ile SOY düzeyi arasında anlamlı fark bulunmamıştır (Tablo 4).

Lise ve üzeri katılımcilarda ortaokul ve altı katılımcılara göre sağlık okuryazarlığı düzeyi 1,96 kat (GA=1,05$3,63, p=0,033)$ daha yüksektir. İş ile ilgili sağlık ve güvenlik talimatlarını anlamada zorluk yaşamadığını belirten çalışanlarda sağlık okuryazarlığı düzeyi 3,10 kat (GA=1,357,07, p=0,007) daha yüksektir (Tablo 5).

\section{TARTIŞMA}

Bir tekstil fabrikasında çalışanların SOY düzeyini tespit etmek, SOY ile ilişkili çeşitli etmenleri belirlemek amacıyla yapılan bu araştırmada, SOY düzeyi çalışanların \% 21,2'sinde yetersiz, \%35,2'sinde sorunlu-sınırlı olarak değerlendirilmiştir.
Tablo 5. Sağlık okuryazarlığı ile ilişkili faktörlerin lojistik regresyon analizi ile incelenmesi*

\begin{tabular}{llccc}
\hline & & $\begin{array}{l}\text { Odds } \\
\text { oranı }\end{array}$ & $\begin{array}{l}\text { Güven } \\
\text { aralığı }\end{array}$ & $\mathbf{p}$ \\
\hline & $\begin{array}{l}\text { Ortaokul ve } \\
\text { alt (R)** } \\
\text { Lise ve üzeri }\end{array}$ & 1,96 & $\begin{array}{c}1,05- \\
3,63\end{array}$ & $\mathbf{0 , 0 3 3}$ \\
$\begin{array}{llll}\text { İşyeri sağlık ve } \\
\text { güvenlik talimatla- } \\
\text { rını anlamada zor- } \\
\text { luk }\end{array}$ & $\begin{array}{l}\text { Evet/Kısmen } \\
\text { (R)** }\end{array}$ & 3,10 & $1,35-$ & $\mathbf{0 , 0 0 7}$ \\
\hline Hayır & & 7,07 & \\
\hline
\end{tabular}

*Modele alınan değişkenler: Algılanan gelir, sağlık algısı, aile tipi, eğitim durumu, işi tehlikeli olarak algılama, işle ilgili sağlık ve güvenlik talimatlarını anlamada zorluk. Nagelkerke R Square: 0.124. Hosmer-Lemeshow testi: $p=0,795$. Doğru sınıflama oranı:\%63,1.

${ }^{* *} \mathrm{R}$ : Referans.

Sezgin tarafından küçük ölçekli işyerlerinde çalışanlarda yapılan araştırmaya göre katılımcıların \%18,0’ının SOY düzeyi yetersiz, \%43,2'sinin SOY düzeyi sorunlu-sınırlıdır [8]. Durmaz ve ark tarafından yapılan çalışmada mermer iş̧̧ilerinde SOY indeks puan ortalaması 31.98 \pm 7.65 olarak bulunmuştur [9]. Tarım işçilerinde Avrupa Sağlık Okuryazarlığı TR Ölçeği (ASOY-TR) puan ortalaması 29,58 $\pm 6,77$ olarak bildirilmiş olup, sorunlu-sınırlı SOY düzeyindedir [10]. Üniversite çalışanlarında yapılan bir araştırmada katılımcıların \%83’ü yeterli SOY düzeyine sahip, \%13 sınırlı SOY düzeyine sahip bulunmuştur [1]. Okyay ve ark tarafından toplum tabanlı yapılan bir çalışmada SOY düzeyi yetersiz veya sorunlu-sınırlı olan kişilerin sıklığı \%68,9 olarak bulunmuştur [11]. Bu araştırmada katılımcıların \% 30,9'unun yetersiz, \%38,0'ının sorunlu-sınırl, \% 23,4’ünün yeterli, \%7,7’sinin mükemmel SOY düzeyi olduğu bildirilmiştir. Araştırmamızda tekstil fabrikasında çalışanlarda yetersiz SOY düzeyi sıklığı düşük iken, sorunlu -sınırlı SOY düzeyi sıklığı Okyay ve ark yaptığı çalışma ile benzerdir. Bakan ve Yıldız, Hazer ve Ateşoğlu ile Berberoğlu ve ark. tarafından yapılan araştırmalarda SOY düzeyinin yetersiz veya sorunlu-sınırlı olma düzeyinin bizim araştırmamızdan daha yüksek olduğu belirtilmektedir $[12,13$, 14]. 
Sağılık okuryazarlığı düzeyi muhtemel olarak araştırmaların yapıldığı yerlere göre farklılık gösterebilir. TÜİK 2020 yılı eğitim istatistiklerine göre Denizli ili okuma yazma oranının en yüksek olduğu iller arasında yer almakta olup, ortaöğretim okullaşma oranının nispeten yüksek olduğu iller arasında yer almaktadır [15]. İş hayatına aktif katılım sosyal etkileşimleri arttıran faktörlerdendir. Sosyal ağ içerisindeki sağlık üzerine bilgi paylaşımları, işs sağlığı ve güvenliği eğitimleri çalışma hayatı içindeki kişilerin SOY düzeyinin yükselmesine neden olabilir. Araştırmamızda yeterli veya mükemmel SOY düzeyinin literatürdeki diğer çalışmalardan yüksek olmasının bir nedeni de katılımcıların aktif çalışma hayatından seçilmiş olması olabilir.

Dünya genelinde yapılan farklı çalışma toplumların sağlık okuryazarlı̆̆ı düzeyinde eğitim düzeyinin önemli bir faktör olduğunu göstermiştir [16, 17, 18]. Nitekim araştırmamıza göre de eğitim düzeyinin yüksek olması, sağlık okuryazarlığı düzeyini arttıran bağımsız bir etmen olarak göze çarpmaktadır. Sezgin'in küçük ölçekli işletmelerde çalışan kişiler üzerinden yürüttüğü çalışmasında lise ve üzeri eğitim düzeyine sahip bireylerde yeterli-mükemmel SOY düzeyi ilkokul düzeyi eğitime sahip bireylere kıyasla 6,64 kat daha fazla bulunmuştur [8]. Durmaz ve ark tarafindan yapılan çalışmada eğitim düzeyi ortaokul ve altı olan mermer işçilerinde, lise ve üzeri olanlara göre SOY indeks puan ortalaması daha düşük bulunmuştur [9]. Tarım işçilerinin SOY düzeyinin değerlendirildiği çalışmada eğitim seviyesi düşük olanlarda Avrupa Sağlık Okuryazarlığı Ölçeği puan ortalaması daha düşük bulunmuştur [10].

Lee ve ark. daha az yılllk eğitime sahip kişilerde SOY düzeyinin de düşük olduğunu bildirmektedir [19]. Okyay ve ark. tarafından yapılan çalışmada eğitim düzeyi azaldıkça SOY puanında artış düşme olduğu bulunmuştur [11]. Çimen ve Temel ile Değerli ve Tüfekçi tarafından yapılan çalışmalarda da eğitim düzeyi azaldıkça sağlık okur- yazarlığı seviyesinin azaldığı bulunmuştur [20, 21]. Halverson ve ark tarafindan yapılan çalışmada da benzer şekilde lise ve altı eğitime sahip kişilerin sağlık okuryazarlığı puanlarının daha düşük olduğu görülmüştür [22].

Araştırmaya göre iş sağlığı ve güvenliği talimatlarını anlamada zorluk yaşamadığını belirtenlerde yeterlimükemmel SOY düzeyi daha yüksek bulunmuştur. Sağlık bilgisine erişmede ve bilgiyi anlamada zorluk yaşayan bireylerin iş sağlığı ve güvenliği ile ilgili eğitimleri, eğitim materyallerini sözlü talimarları anlamada zorluk yaşaması beklendik bir sonuçtur. Araştırma bulgumuz SOY düzeyinin sadece klinik ortamda bireylerin hastalığı hakkında bilgileri anlama ve tedaviye uyumu için değil, iş sağlığı ve güvenliği açısından da önemli bir unsur olduğunu göstermiştir. İşyerleri sağlık okuryazarlığının geliştirilmesi için uygun ortamlardır. Düşük gelirli çalışanlara yönelik müdahaleler için işyerlerinde sağılık okuryazarlığının geliştirilmesi sağlıkta eşitsizlikleri azaltmada faydalı olacaktır. İşyerlerinde sağlık okuryazarlığının geliştirilmesi sadece çalışanlar için değil, iş yeri için de önemli bir değer yaratacaktır [23].

Araştırmanın bazı sınırlııkları bulunmaktadır. Araştırmada ulaşılan örneklem büyüklüğü küçüktür. Bir tekstil fabrikasında çalışanlar araştırmaya alınmıştır. Benzer sektörde çalışan bütün bireyleri temsil etmemektedir. Buna rağmen araştırmanın güçlü yönleri de bulunmaktadır. Sağlık okuryazarlığı düzeyi Türkiye’de geçerlik ve güvenirliği gösterilmiş bir ölçek ile değerlendirilmiştir.

\section{SONUÇ}

Sonuç olarak, tekstil fabrikasında çalışanların yarııında sağlık okuryazarlığı düzeyi yetersiz veya sorunlu-sınırlıdır. Eğitim düzeyi sağlık okuryazarlı̆̆ı düzeyi için önemli bir belirleyicidir. İşs sağlığı ve güvenliği talimatlarını anlamada zorluk yaşayan çalışanların sağlık okuryazarlığı düzeyi düşüktür. İşyerlerinde sağlık okuryazarlığı düzeyini geliştir- 
meye yönelik müdahalelere ihtiyaç vardır. Gerek iş sağlı̆̆ ve güvenliği eğitimleri gerekse işyeri sağl1k eğitimleri planlanırken çalışanların sağlık okuryazarlığı düzeyi göz önünde bulundurulmalıdır. Sağlık bilgileri verilirken çalışanlara açık ve basit bir dil kullanılması sağlık eğitimlerinin amacına ulaşmasını sağlayabilir.

YAZAR KATKıLARI: Yazarların katkıları eşit düzeydedir.

TeşeKкüR: Araştırmaya olan katkılarından dolayı Dr. Deniz NALBANTOĞLU'na sonsuz teşekkürlerimizi sunarı.

ÇıKAR ÇATIşması: Yazarlar arasında herhangi bir çıkar çatışması yoktur. Makalede araştırma ve yayın etiğine uyulmuştur.

Finansal Destek: Bu çalışmada herhangi bir kişi, kurum veya kuruluştan finansal destek alınmamıştır.

Eтік Комітte Onayı: Çalışma için 16.07.2019 tarihinde 13 numarası ile Pamukkale Üniversitesi Tıp Fakültesi Girişimsel Olmayan Klinik Araştırmalar Etik Kurulu'ndan onay alınmıştır.

\section{KAYNAKÇA}

[1] Karl, J. I., \& McDaniel, J. C. (2018). Health literacy deficits found among educated, insured university employees. Workplace Health \& Safety, 66(9), 419427.

[2] Cajita, M. I., Cajita, T. R., \& Han, H. R. (2016). Health literacy and heart failure: a systematic review. The Journal of Cardiovascular Nursing, 31(2), 121.

[3] Wong, B. K. (2012). Building a health literate workplace. Workplace Health \& Safety, 60(8), 363369.

[4] Berkman, N. D., Sheridan, S. L., Donahue, K. E., Halpern, D. J., \& Crotty, K. (2011). Low health literacy and health outcomes: An updated systematic review. Annals of Internal Medicine, 155, 97-107.

[5] Parks, C. I., Chikotas, N. E., \& Olszewski, K. (2012). A comprehensive review of the healthy people 2020 occupational safety and health objectives:
Part 1. Tools for the occupational health nurse in goal attainment. Workplace Health \& Safety, 60(1), 33-42.

[6] Cho, M., Lee, Y. M., \& Lee, H. (2020). Factors Associated with the Health Literacy on Social Determinants of Health: A Focus on Socioeconomic Position and Work Environment. International Journal of Environmental Research and Public Health, 17(18), 6663.

[7] Shannon, H. A., \& Parker, A. W. (2020). Evaluation of a Health Literacy Instrument Designed for the Mining Industry. HLRP: Health Literacy Research and Practice, 4(2), 84-93.

[8] Sezgin, Ö. (2019). Isparta Gül Küçük Sanayi Sitesi Küçük Ölçekli İşyeri Çalışanlarında Sağlık Okuryazarlığı Düzeyi ve İlişkili Faktörler, Tıpta Uzmanlık Tezi, Süleyman Demirel Üniversitesi Tıp Fakültesi, Isparta.

[9] Durmaz, S., Sürücü, E., \& Özvurmaz, S. Mermer Fabrikası İşçilerinde Sağlık Okuryazarlığı, Sağlık Algısı Düzeyleri ve İlişkili Faktörlerin Belirlenmesi. Medical Sciences, 15(3), 81-91.

[10] Koç, N. (2020). Tarım İşçilerinin Yaşam Koşulları, Sağlık Algısı, Sağlık Okuryazarlığı Düzeyleri ve İlişkili Faktörler, Yüksek lisans tezi, Aydın Adnan Menderes Üniversitesi Sağlık Bilimleri Enstitüsü, Aydın.

[11] Okyay, P., Abacıgil, F. 2016. Türkiye Sağlık Okuryazarlığı Ölçekleri Güvenilirlik ve Geçerlilik Çalışmas1,https://sbu.saglik.gov.tr/Ekutuphane/kitaplar/ SOYA\%20RAPOR.pdf, son erişim tarihi.10.08.2021.

[12] Bakan, A. B., \& Yıldız, M. (2019). 21-64 Yaş grubundaki bireylerin sağlık okuryazarlık düzeylerinin belirlenmesine ilişkin bir çalışma. Sağlık ve Toplum, 29(3), 33-40.

[13] Hazer, O., \& Ateşoğlu, L. (2019). Yaşlilarda Sağlık Okuryazarlığının Başarılı Yaşlanma Ü̉zerine Etkisi: Ankara İli Örneği. Turkiye Klinikleri Internal Medicine Nursing-Special Topics, 5(2), 48-56.

[14] Berberoğlu, U., Öztürk, O., İnci, M. B., \& Ekerbiçer, H. Ç. (2018). Bir aile sağlığı merkezine kayıtlı 18 -65 yaş grubu bireylerdeki sağlık okuryazarlığı durumunun değerlendirilmesi. Sakarya Tıp Dergisi, 8(3), 575-581.

[15] Türkiye İstatistik Kurumu (TÜİK). https:// biruni.tuik.gov.tr/ilgosterge/?locale=tr (27.12.2021).

[16] Xie, Y., Ma, M., Zhang, Y. N., \& Tan, X. (2019). Factors associated with health literacy in rural areas of Central China: structural equation model. BMC 
Health Services Research, 19(1), 300.

[17] Liu, Y. B., Liu, L., Li, Y. F., \& Chen, Y. L. (2015). Relationship between health literacy, health-related behaviors and health status: A survey of elderly Chinese. International Journal of Environmental Research and Public Health, 12(8), 9714-9725.

[18] Protheroe, J., Whittle, R., Bartlam, B., Estacio, E. V., Clark, L., \& Kurth, J. (2017). Health literacy, associated lifestyle and demographic factors in adult population of an English city: a cross-sectional survey. Health Expectations, 20(1), 112-119.

[19] Lee,S.Y.D., Tsai,T.I., Tsai ,Y.W., Kuo,K.N., (2010). Health Literacy, Health Status, and Healthcare Utilization of Taiwanese Adults: Results from A National Survey. BMC Public Health, 10(614).

[20] Çimen,Z.ve Temel,A.B.,(2017). Kronik Hastalığı Olan Yaşlı Bireylerde Sağlık Okuryazarlığı ve Sağlık Algısı İlişkisi ve Sağlık Okuryazarlığını Etkileyen Faktörlerin İncelenmesi. Ege Üniversitesi Hemşirelik Fakültesi Dergisi, 33(3):105-25.

[21] Değerli, H., \& Tüfekçi, N. (2018). Toplumun Sağlık Okuryazarlık Düzeyinin Belirlenmesi. Avrasya Uluslararası Araştırmalar Dergisi, 6(15), 467-488.

[22] Halverson, J. L., Martinez-Donate, A. P., Palta, M., Leal, T., Lubner, S., Walsh, M. C. \& TrenthamDietz, A., (2015). Health Literacy and HealthRelated Quality of Life Among A PopulationBased Sample of Cancer Patients. Journal of Health Communication, XX,11:1320-1329

[23] Larsen, A. K., Holtermann, A., Mortensen, O. S., Punnett, L., Rod, M. H., \& Jørgensen, M. B. (2015). Organizing workplace health literacy to reduce musculoskeletal pain and consequences. BMC Nursing, 14(1), 1-13. 